\title{
Contrasting variation in aerosol optical properties during dust episodes in the Middle East and Southwest Asia: Model results and ground measurement
}

\author{
Khan Alam $^{1, *}$, Maqbool Ahmad ${ }^{2}$ \\ ${ }^{1}$ Department of Physics, University of Peshawar, Khyber Pakhtunkhwa, Pakistan \\ ${ }^{2}$ Department of Meteorology, COMSATS University Islamabad, Pakistan
}

\begin{abstract}
Dust storms deteriorated air quality over the Gulf Region, Iraq, Iran, and Pakistan during the last decade. The purpose of this study is to investigate the changes in aerosol optical and radiative properties during a dust episode over the various locations in the Middle East and Southwest Asia using data from the MODerate resolution Imaging Spectroradiometer (MODIS) and the Aerosol Robotic Network (AERONET) during March, 2012. Maximum aerosol optical depth (AOD) values were found to be 2.18, 1.30, 4.33 and 1.80 over Lahore, Kanpur, Kaust, and Mezaira, respectively. The Volume Size Distributions, Single Scattering Albedo, Refractive Index, and Asymmetry parameter indicated that coarse mode aerosols were predominant relative to fine mode aerosols during the dust event. The average shortwave aerosol radiative forcing (ARF) values at the earth's surface were found to be $-96 \pm 45 \mathrm{~W} \mathrm{~m}^{-2},-86 \pm 22 \mathrm{~W} \mathrm{~m}^{-2},-77 \pm 51 \mathrm{~W} \mathrm{~m}^{-2}$, and $-75 \pm 40 \mathrm{~W} \mathrm{~m}^{-2}$, over Lahore, Kanpur, Kaust and Mezaira, respectively. Likewise, the averaged ARF values over Lahore, Kanpur, Kaust and Mezaira at the top of the atmosphere (TOA) were found to be $-45 \pm 25 \mathrm{~W} \mathrm{~m}^{-2},-27 \pm 9 \mathrm{~W} \mathrm{~m}^{-2},-41 \pm 29 \mathrm{~W} \mathrm{~m}^{-2}$, and $-75 \pm 40 \mathrm{~W} \mathrm{~m}^{-2}$, respectively. The large differences between surface and TOA forcing produced significant heating within the atmosphere.
\end{abstract}

\section{Introduction}

Dust has significant impacts on air quality, human health and climate. Dust particles both absorb and scatter the solar radiations, resulting warming and cooling of the atmosphere, respectively [1,2]. The variation of dust in the atmosphere can affect a wide range of disciplines. Among them human health is impacted by inhaling the fine particles (below $2.5 \mu \mathrm{m}$ ) of dust through respiration [3]. The presence of dust (e.g. aerosols) may cause the variation in the formation of warm and mixed-phase clouds on a large scale due to the radiative and microphysical forcings [4,5]. During the last decades, dust storms originated from the Sahara Desert, the Middle East and Thar Desert, have significantly deteriorated air quality in the Middle East and Southwest Asia. Dust particles have an effect on aerosol optical and radiative properties. In-depth analysis of aerosol optical properties during dust episodes is sparse and needs further analysis in order to reduce the uncertainties in radiative forcing. Therefore, it is necessary to analyze aerosol optical and radiative properties during dust storm events. In the present study dust aerosol optical and radiative properties have been investigated in four locations in the Middle and Southwest Asia using satellite and ground based observations from $1^{\text {st }}$ to $31^{\text {st }}$ March, 2012.

*Corresponding author: khanalam@uop.edu.pk

\section{Methodology}

\subsection{Study site and meteorology}

The map of the study area is shown in Figure 1. The study sites, namely, Lahore and Kanpur, are located in Southwest Asia, whereas, Kaust and Mezaira are located in the Middle East region. During spring and summer seasons, dust particles are dominant aerosol type at these sites. During mid of March, a low pressure zone is created in eastern Syria and high pressure zone in northern Iraq, consequently, winds are accelerated towards Iraq, which cause super dust storms in the region [6].

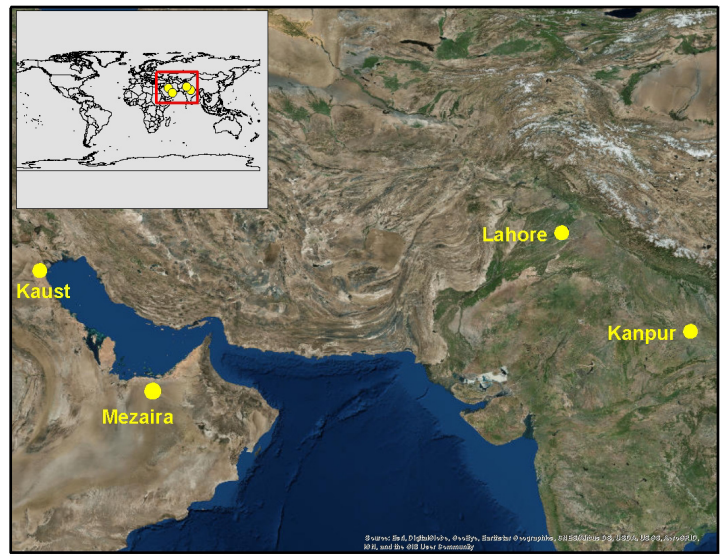

Figure 1. Map of the Study Area. 


\subsection{Instrumentation}

\subsubsection{Aerosol Robotic Network}

The AErosol RObotic NETwork (AERONET) is a ground based aerosol network system at more than 400 sites all over the world [7,8]. It holds a sun photometer sensor that deals with sun and sky irradiances directly in the range of several wavelengths. The computation of radiations is carried out at among the spectral range of 340-1020 nm, whereas the sky irradiance observations are computed at different spectral channels (i.e. 440, 670,870 and $1020 \mathrm{~nm}$ ). Further, these radiances are analyzed to identify the aerosol absorption [9]. AERONET provides three level data; Level 1.0 (unscreened), Level 1.5 (cloud screened) and Level 2.0 (cloud screened and quality assured). In the present work, AERONET Level 2.0 direct (Aerosol Optical Depth and water vapors) and inversion (Single Scattering Albedo and Asymmetry Parameter) products are used.

\subsubsection{Cloud Aerosol LIDAR and Infra-red Pathfinder Satellite Observation}

Among various earth's observatories, Cloud Aerosol LIDAR and Infra-red Pathfinder Satellite Observation (CALIPSO) is a part of A-Train instruments. It was launched on April 28, 2006 with its equatorial crossing times of $1: 30$ and 13:30. Its repeat cycle is 16 days. The CALIPSO space-born lidar gives details about aerosols distribution and clouds. Its unique feature is that it provides vertical profiles of aerosols and clouds on micro and macro scales [10]. The unique feature is basically the polarization capability that distinguishes dust from other aerosols. In the present study, the CALIPSO aerosol sub-type profile was analyzed during March, 2012 on the selected dusty days over the study region.

\subsubsection{Moderate Resolution Imaging Spectroradiometer}

Moderate Resolution Imaging Spectroradiometer (MODIS) is a space borne sensor mounted on Terra and Aqua satellites. These satellites were launched by NASA and are operating since 2000 and 2002, respectively. MODIS has a swath of $2330 \mathrm{~km}$. The crossing times on equator for the Terra and Aqua are 10:30 and 13:30, respectively [11]. MODIS measures aerosols on land and ocean at two different wavelengths [1]. It can be used to investigate aerosol distributions at any scale. In the present study, surface albedo data is utilized for radiative forcing calculation.

\subsection{Radiative Forcing Calculation}

SBDART (Santa Barbara DISORT Atmospheric Radiative Transfer) is a computer code developed at the University of California. SBDART modelling can be used in a broad variety of problems in various studies of remote sensing and atmospheric energy budget. This model can be used to calculate the parallel radiation in a clear and cloudy atmosphere at the earth's surface and within the atmosphere [12]. This tool deals with the radiation and accomplishes a wide variety of radiative transfer calculation in the short and long wavelength regions [13]. During its calculation the emission and scattering of thermal radiation can be scaled from different heights and direction in the atmosphere. The INPUT file is comprised of several parameters like spectral aerosol optical depth, single scattering albedo, asymmetry parameter, surface reflectance, columnar ozone and water vapor.

\section{Results and Discussion}

\subsection{Aerosol Optical Properties}

\subsubsection{Aerosol Optical Depth (AOD)}

The box-whisker plot shows the variability of Aerosol Optical Depth (AOD) provided by AERONET sun photometers in the study region as shown in Figure 2. The results revealed that AOD values at $676 \mathrm{~nm}$ were found to be high in dusty days as compared to non-dusty days. The AOD values are in the range of 0.20 to 2.18 , 0.21 to $1.30,0.14$ to 4.33 , and 0.04 to 1.80 , over Lahore, Kanpur, Kaust, and Mezaira, respectively. The corresponding averaged values at these sites were found to be $0.60 \pm 0.40,0.50 \pm 0.20,0.61 \pm 0.70$, and $0.59 \pm 0.41$, respectively, during March, 2012.

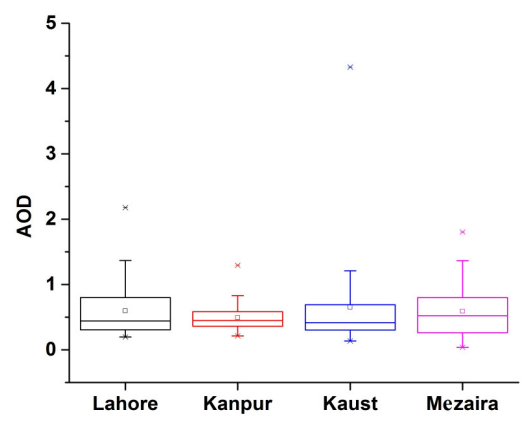

Figure 2. Box-whisker plots summarizing the variation in AOD. Each box indicates the 25 th and 75 th percentiles and the whiskers shows the 5 th and 95 th percentiles. The vertical lines show the standard deviation from the mean value. The solid circle inside each box and the horizontal lines represent the mean and median values, respectively. The crosses above and below the boxes indicate the maximum and minimum values, respectively. The Level-2 data during March, 2012 for Lahore (26 days), Kanpur (30 days), Kaust (30 days) and Mezaira (31 days) were obtained from AERONET at each location.

\subsubsection{Aerosol volume size distribution}

Aerosol volume size distribution (AVSD) from AERONET is used to categorize aerosols into fine and coarse modes. Figure 3 depicts the AVSD at Lahore, Kanpur, Kaust and Mezaira. The results showed that AVSD is significantly fluctuating in dusty and non-dusty days. There is significant variation in AVSD in coarse mode as compared to fine mode particles. 

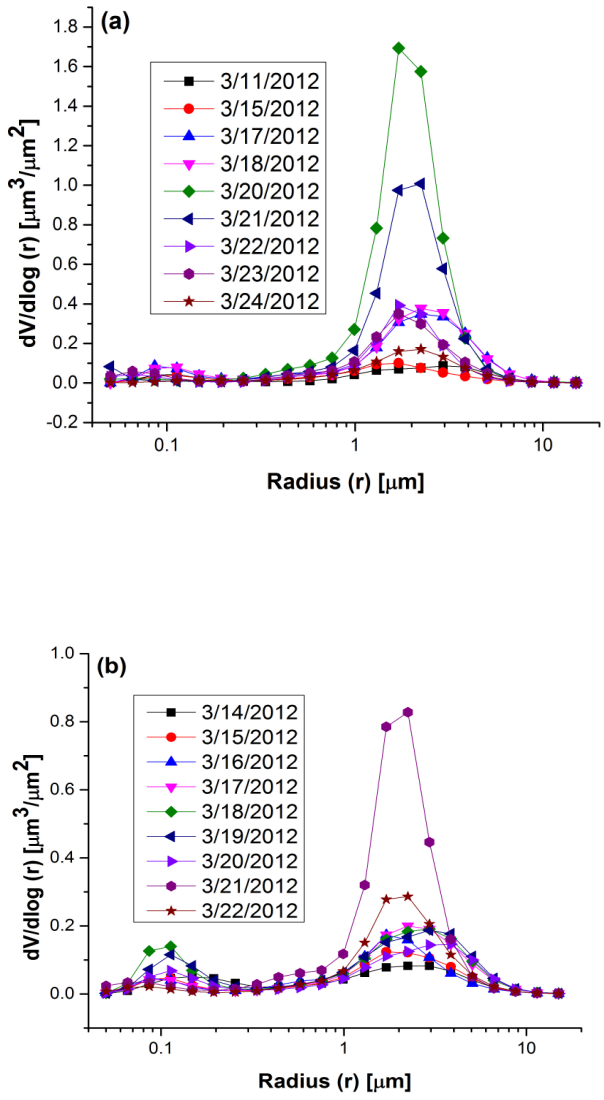
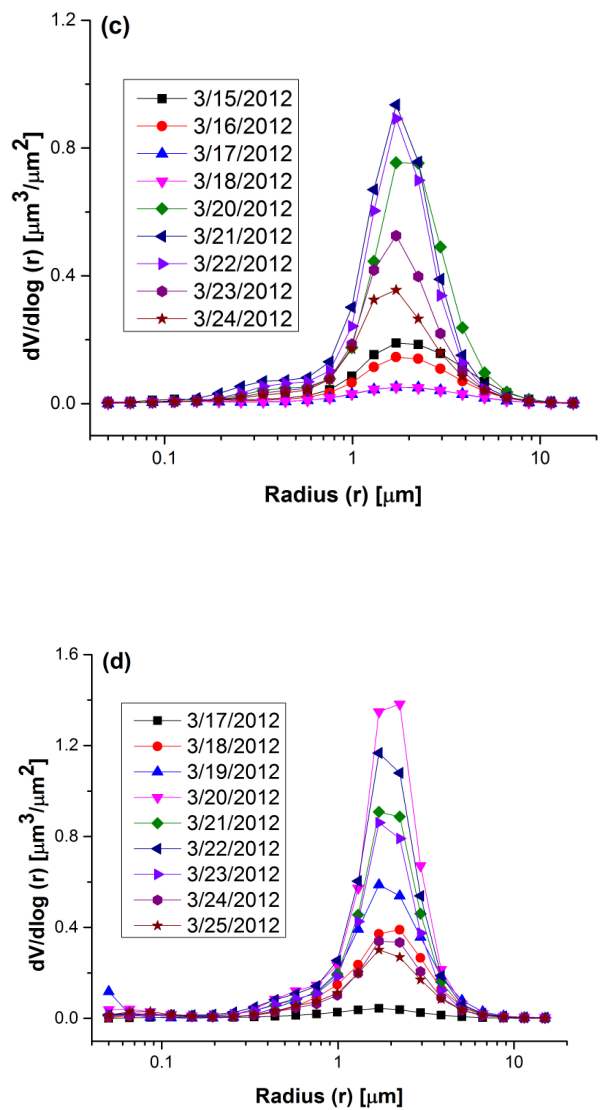

Figure 3. Aerosol volume size distribution over (a) Lahore, (b) Kanpur, (c) Kaust, (d) Mezaira during 9 dusty and non-dusty days in March, 2012.

\subsubsection{Asymmetry Parameter (ASY)}

The ASY provides useful information about scattering and absorption properties of dust aerosol. The highest asymmetry parameter $(\sim 0.76)$ is noticed in Mezaira with an associated lowest value ( 0.66) in Kanpur (see Figure $4)$. The overall analysis revealed the highest value of ASY in Mezaira and Kaust. However, the contrasting behavior is observed in Kanpur.

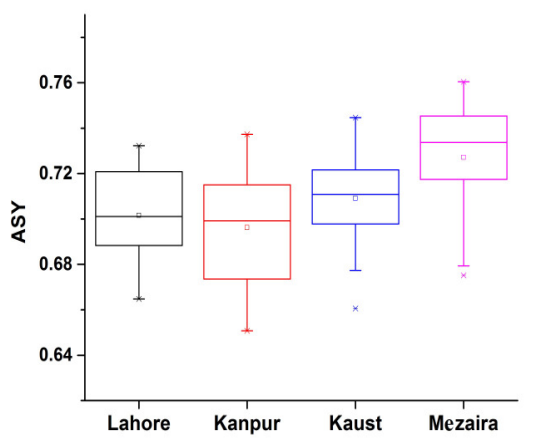

Figure 4. Same as Figure 2, but for ASY at $676 \mathrm{~nm}$.

\subsubsection{Single scattering albedo}

Like ASY, SSA provides important information about the scattering and absorption characteristics of dust aerosol. The SSA and ASY are important input parameters and used for radiative forcing calculation. Figure 5 showed significant variation in SSA during dusty and non-dust days. High SSA values greater 0.90 are correspond to dust aerosols, whereas, low SSA values $(<0.90)$ correspond to polluted dust and urbanindustrial aerosol.

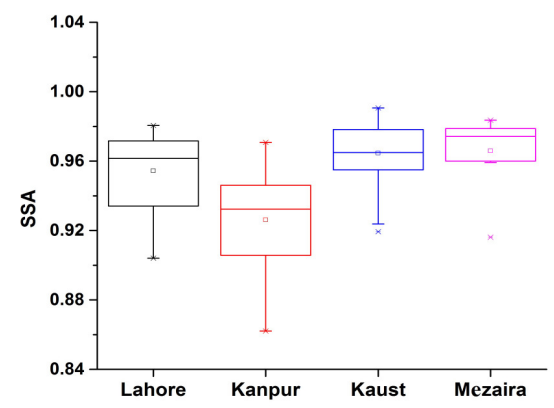

Figure 5. Same as Figure 2, but for SSA at $676 \mathrm{~nm}$. 


\subsubsection{Aerosol subtypes profile}

Figure 6 depicts the dust, polluted dust, and smoke over the study region retrieved from CALIPSO satellite on $20^{\text {th }}, 21^{\text {st }}$, and $23^{\text {rd }}$ March, 2012. The aerosol subtypes profile revealed that the dust aerosol extending up to a height of about $8 \mathrm{~km}$ from the surface (see Figure 6). It is also clear from the figure that the plumes of dust and polluted dust are dominant over these regions.

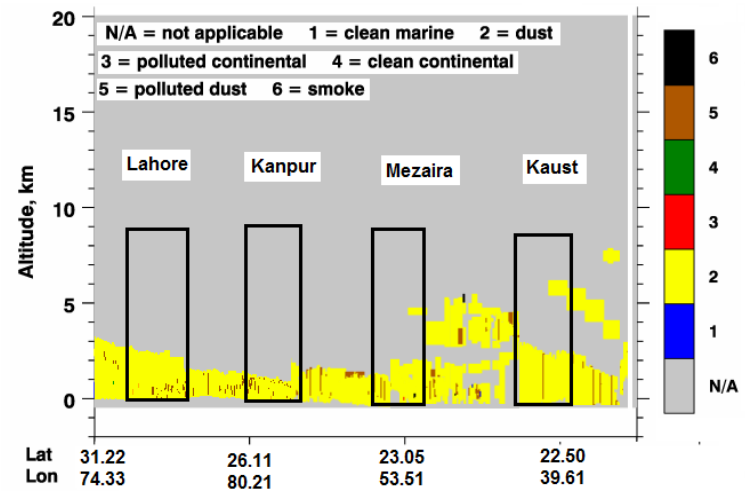

Figure 6. Classification of Aerosol subtypes profiles retrieved from CALIPSO polar orbiting satellite on $20^{\text {th }}, 21^{\text {st }}, 21^{\text {st }}$ and $23^{\text {rd }}$ March, 2012 over Lahore, Kanpur, Mezaira and Kaust, respectively.

\section{Radiative Forcing}

The Aerosol Radiative Forcing (ARF) is the net flux down minus up with and without aerosol. In the present study ARF values were calculated at the earth's surface, at the top of the atmosphere (TOA) and within the atmosphere using SBDART model during March, 2012. The main input parameters to the model are AOD, SSA, ASY, water vapor and surface albedo. The mean ARF at the earth's surface, TOA and within the atmosphere are given in Table 1. The ARF values at the earth's surface were found to be in the range from -45 to -194 $\left(-96 \pm 45 \mathrm{~W} \mathrm{~m}^{-2}\right),-48$ to $-142\left(-86 \pm 22 \mathrm{~W} \mathrm{~m}^{-2}\right),-26$ to $-250\left(-75 \pm 40 \mathrm{~W} \mathrm{~m}^{-2}\right)$, and -15 to $-158\left(-75 \pm 40 \mathrm{~W} \mathrm{~m}^{-2}\right)$ over Lahore, Kanpur, Kaust and Mezaira, respectively. Similarly, ARF at TOA at these sites were ranged from -15 to $-105\left(-45 \pm 25 \mathrm{~W} \mathrm{~m}^{-2}\right),-13$ to $-59\left(-27 \pm 9 \mathrm{~W} \mathrm{~m}^{-2}\right)$, -13 to $-130\left(-41 \pm 29 \mathrm{~W} \mathrm{~m}^{-2}\right)$ and 3 to $-45(-11 \pm 12$ $\mathrm{W} \mathrm{m^{-2 }}$ ), respectively. The large differences in surface and TOA forcing produced atmospheric forcing of $51 \pm 22,59 \pm 15,36 \pm 23$, and $63 \pm 33 \mathrm{~W} \mathrm{~m}^{-2}$ over Lahore, Kanpur, Kaust and Mezaira, respectively.

Table 1. Mean Aerosol Radiative Forcing $\left(\mathrm{W} / \mathrm{m}^{2}\right)$ over Lahore, Kanpur, Kaust and Mezaira during March, 2012.

\begin{tabular}{cccc}
\hline Locations & Surface & TOA & ATMOS \\
\hline Lahore & $-96 \pm 45$ & $-45 \pm 25$ & $51 \pm 22$ \\
Kanpur & $-80 \pm 21$ & $-27 \pm 09$ & $45 \pm 15$ \\
Kaust & $-77 \pm 44$ & $-41 \pm 26$ & $36 \pm 19$ \\
Mezaira & $-74 \pm 38$ & $-11 \pm 08$ & $63 \pm 28$ \\
\hline
\end{tabular}

\section{Conclusion}

The aerosol properties in terms of their size distribution, SSA, and ASY over Lahore, Kanpur, Kaust, and Mezaira were analyzed. Following were the main observations of the study in hand.

- The significant variation in AOD was observed in all four sites during dusty and non-dusty days.

- The AVSD provides the contrasting behaviour of dust aerosol in the study period

- SSA and ASY provide scattering and absorbing information during dusty and non-dusty days.

- The CALIPSO data are utilized to verify the existence of dust in the region.

The ARF at the surface and TOA produce cooling effects, whereas, within the atmosphere, it produces significant heating effects.

\section{References}

1. K. Alam, R. Khan, T. Blaschke, A. Mukhtiar, J. Atmos. Sol.-Terr. Phys. 107, 104-112 (2014)

2. R.L. Miller, J. Perlwitz, I. Tegen, J. Geophy. Res. 109, D24 (2004)

3. G.J. Prescott, G.R. Cohen, R.A. Elton, F.G.R. Fowkes, R.M. Agius, Environ. Med. 55, 697-704 (1998)

4. V. Jha, W.R. Cotton, G.G. Carrio, R. Walko, Adv. Meteorol. (3041893) (2018)

5. C.A. DeMott, C. Stan, D.A. Randall, M.D. Branson, J. Climate 27(13), 4970-4995 (2014)

6. K. Alam, T. Trautmann, T. Blaschke, \& F. Subhan, Remote Sens Environ, 143, 216-227 (2014)

7. H. Bibi, K. Alam, S. Bibi, Atmos. Environ. 163, 166-181 (2017)

8. B.N. Holben, T.F. Eck, I. Slutsker, D. Tanre, J.P. Buis, A. Setzer, E. Vermote, J.A. Reagan, Y. Kaufman, T. Nakajima, F. Lavenu, I. Jankowiak, and A. Smirnov, Rem. Sens. Env. 66 (1998)

9. H. Bibi, K. Alam, S. Bibi, Atmos. Res. 181, 106114 (2016)

10. D.M. Winker, J. Pelon, J.A. Coakley Jr, S.A. Ackerman, R.J. Charlson, P.R. Colarco, P. Flamant, Q. Fu, R.M. Hoff, C. Kittaka, and T.L. Kubar. B Am Meteorol Soc. 91(9), 1211-1230 (2010).

11. R.C. Levy, L.A. Remer, O.J. Dubovik, J. Geophys. Res. 112, D13 (2007)

12. P. Ricchiazzi, S. Yang, C. Gautier, D.B. Sowle, Am. Meteorol. Soc. 79(10), 2101-2114 (1998)

13. S. Bibi, K. Alam, F. Chishtie, H. Bibi, Atmos. Environ. 150, 126-135 (2017) 